\title{
Gamolenic Acid
}

National Cancer Institute

\section{Source}

National Cancer Institute. Gamolenic Acid. NCI Thesaurus. Code C68369.

A polyunsaturated long-chain fatty acid with an 18-carbon backbone and exactly three double bonds, originating from the 6th, 9th and 12th positions from the methyl end, with all double bonds in the cis- configuration. 